\title{
Práticas integrativas e complementares grupais e o diálogo com a educaçáo popular
}

\author{
Integrative and complementary practices and dialogue with popular education
}

\author{
Maria Valquiria Nogueira do Nascimento ${ }^{\mathrm{I}}$ \\ Isabel Fernandes de Oliveira ${ }^{\text {II }}$
}

\begin{abstract}
Resumo
O presente estudo consistiu em analisar a inserção das PIC’s Grupais como estratégia de cuidado e atenção integral à saúde e as possibilidades de diálogo com a educação popular em Unidades Básicas. Dos equipamentos contactados, 22 realizavam PIC’s Grupais, a saber: relaxamento, meditação, yoga, tai chi chuan, grupos de suporte mútuo, tenda do conto, grupo de prosa com mulheres, grupo de bordadeiras, grupo de idosos, grupo de caminhadas, grupo de terapia e arte, grupos de contação de histórias, terapia comunitária e teatro do oprimido. A educação popular pode ser instrumento de reorientação da atenção à saúde e globalidade das PIC's Grupais, com base numa perspectiva participativa, criativa, dialogada e emancipadora.
\end{abstract}

Palavras chave: Práticas integrativas e complementares; grupo; integralidade; educação popular; serviços de saúde da atenção básica

\begin{abstract}
The present study consisted in to analyze the insertion of Group PICs as a strategy of care and integral health care and the possibilities of dialogue with popular education in Basic Units. Of the equipment contacted, 22 made group PICs, namely: relaxation, meditation, yoga, tai chi chuan, mutual support groups, tale tent, prose group with women, group of embroiderers, group of elderly people, group of walks, group of therapy and art, storytelling groups, community therapy and the theater of the oppressed. Popular education can be an instrument to reorient attention to health and globality of group PIC's, based on a participatory, creative, dialogic and emancipatory perspective.
\end{abstract}

Keywords: Integrative and complementary practices; group; integrality; popular education; basic health care services.

\footnotetext{
${ }^{\mathrm{I}}$ Universidade Federal de Campina Grande. Docente do Curso de Psicologia da Universidade Federal de Campina Grande.

II Universidade Federal do Rio Grande do Norte. Docente do Cursp de Pós-Graduação em Psicologia na Universidade Federal do Rio Grande do Norte
}

É recorrente nos serviços de saúde a entrada de pessoas em busca de atendimento, muitas vezes, com queixas relacionadas a um mal estar generalizado, cuja sintomatologia não se enquadra numa nosografia tradicional. De acordo com Valla (2001), Fonseca, Guimarães e Vasconcelos (2008) e Vasconcelos (2008, 2010), esse tipo de manifestação de adoecimento pode ser nomeado como "sofrimento difuso", como forma de se referir a problemáticas e queixas inespecíficas relacionadas a questôes psicossociais importantes, como a ausência de redes de apoio social, problemas que dizem respeito às relações familiares, laborativas, sociais e econômicas dos usuários dos serviços de saúde. Essas temáticas não são, muitas vezes, explicadas sob as lentes dos saberes biomédicos ou psicológicos, motivo por que os profissionais de saúde são convocados a reorientar as suas açóes e articular diferentes concepçóes sobre o processo saúde-doença. Nesse sentido, as Práticas Integrativas e Complementares [PIC's] apresentam-se como ferramentas que podem propiciar a recomposição da integralidade em saúde, por meio da qual as pessoas e grupos sociais protagonizam um maior controle sobre suas vidas. $\mathrm{O}$ presente artigo pretende apresentar os resultados de um estudo que consistiu em analisar a inserção das PIC's Grupais como estratégia de cuidado e assistência integral à saúde na atenção básica, na perspectiva de compreender as possibilidades de diálogo com a educação popular ${ }^{1}$.

\section{As PIC's no Contexto do SUS}

O Ministério da Saúde [MS], em 2006, através da Portaria GM n ${ }^{\circ}$ 971, instituiu as PIC's como política de governo, com vistas a ampliar a pluralidade terapêutica, antes restrita aos setores privados. Dentre as práticas previstas estavam: a homeopatia, acupuntura, medicina tradicional chinesa, termalismo, medicina antroposófica, plantas medicinais e fitoterapia, Reiki e Lian Gong. Mais recentemente, a portaria $\mathrm{n}^{\circ} 849$ incluiu a arterapia, auyurveda, biodança, dança circular, meditação, musicoterapia, naturopatia, osteopatia, quiropraxia, reflexoterapia, reiki, shantala e yoga à política nacional (Brasil, 2006,2017).

1 Segundo as bases Freirianas, são práticas educativas que se propõem a ser libertadoras e tomam como ponto de partida as relaçôes dialógicas, em defesa de que o conhecimento é construído junto com as pessoas, num processo colaborativo, de articulação e confronto de saberes. Para tanto, é interessante considerar essa educaçáo no contexto cotidiano, no interior de sua morada, que é a cultura (Freire, 1967, 2005; Brandão, 2012). 
As PIC's representam um grupo de sistemas médicos e terapêuticos de cuidado à saúde, práticas e produtos que não são presentemente considerados parte da biomedicina e são orientadas pelos seguintes princípios: escuta acolhedora, desenvolvimento do vínculo terapêutico, integraçáo do ser humano com o ambiente e a sociedade, visão ampliada do processo saúde-doença, promoção global do cuidado humano, autocuidado, entre outros (Barros e Tesser, 2008). Essas modalidades terapêuticas têm se destacado por incitar mudanças em hábitos de vida, com caráter de promoção e estimular a participação ativa da pessoa frente à sua doença. Um os principais fatores de transformação é a inversão do paradigma da doença para o de saúde, uma menor dependência dos profissionais e dos remédios, e a autonomia em busca pelo cuidado (Luz, 2009, 2012 e Pinheiro \& Mattos, 2004).

Dessa forma, dentre as diversas PIC's desenvolvidas nos serviços de saúde, este estudo se ocupou das práticas que são de caráter grupal. De acordo com Valla (2001) e Vasconcelos (2013), ao participarem de algum grupo de apoio social no qual passam pelos mesmos problemas ou vivem situaçôes que afetam o bem-estar e a saúde, as pessoas estabelecem um intercâmbio de vivências que é benéfico tanto para quem ajuda quanto para aquele que é beneficiado com a vivência dos outros participantes. Produz-se, assim, um sentimento de igualdade, de utilidade social e competência individual e grupal, de modo que os apoios disponibilizados por determinados grupos ou organizaçôes sociais podem contribuir para proporcionar fatores de proteção contra o surgimento de doenças.

\section{As Práticas Integrativas e Complementares Grupais e as Possibilidades de Diálogo com a Educação Popular}

Este estudo tomou como ponto de partida a produção de cuidado em saúde com origens na hegemonia da biomedicina, cuja prática desvaloriza fatores subjetivos e sociais associados ao processo saúde-doença. Com uma forte atuaçáo na medicalização social ${ }^{2}$ e na centralizaçáo do saber-poder dos profissionais de saúde, a ação biomédica reduz o potencial cultural e de autonomia das pessoas para lidarem com as situaçôes de

2 Segundo Foucault (2002), consiste "na ação do Estado ao controlar corpos da mesma forma que controla a população" (p. 293). A rigor, são estratégias de assujeitamento que podem se apresentar em formato de discursos e práticas de instituiçóes, a exemplo da medicalização, que, a partir da normatização de determinados modos e estilos de vida, do consumo de medicamentos e de uma certa regulação médicosanitária da vida, ordena a relaçáo entre Estado e os sujeitos. adoecimento. Nesse sentido, apostamos na educação popular como instrumento de reorientação da atenção à saúde e globalidade das práticas, especialmente das PIC's Grupais, com base numa perspectiva participativa, dialogada e emancipadora. Para tanto, faz-se necessário a quebra dos poderes centralizadores para dar lugar a uma relação educativa e dialógica com a população na qual a valorização, articulação e confrontação de outros saberes tornam-se imperativas (Vasconcelos, 2010).

Dentre os contextos orientados pela dimensão educativa, dialógica e emancipadora da educação popular, o campo da saúde tem se constituído como um espaço fértil para uma relaçáo de mais proximidade com as classes populares, ao mesmo tempo que rompe com o modo autoritário e normatizador de produção de saúde, pautado num modo de cuidado que não considera a participaçáo das pessoas na construção de formas para lidar com os processos de adoecimento, portanto, não parte das necessidades dos sujeitos (Vasconcelos, 2010). A adoção dessa concepção para as práticas de saúde significa um desprendimento do poder dos profissionais com saberes gestados na academia e para a qual o conhecimento popular tem menor valor, para uma atitude educadora que suscita processos participativos. Para tanto, o diálogo se impóe como condição determinante numa relação que se pretende igualitária. Sem dúvida, as iniciativas de educação popular foram e são, ainda hoje, absolutamente importantes para a inauguração de uma cultura de mais proximidade com as pessoas e a transformação da relação autoritária da educação em saúde. Nessa direção, açôes como as de PIC's Grupais foram introduzidas nos serviços como forma de superar a hegemonia do biologicismo e reorientar a globalidade das açóes, garantindo uma pluralidade terapêutica na qual as pessoas têm autônomo poder de participar das decisóes que dizem respeito ao seu processo saúde-doença. Tais práticas apresentam um caráter contra-hegemônico ao diversificarem as referências de saber e as técnicas autônomas e heterônomas de cuidado de si e dos outros, constituindo-se em possibilidade de cuidado para grande parte das situações comuns de adoecimento, típicas da APS (Tesser, 2010).

\section{MÉTODO}

\section{Cenário e Grupo Sujeito: Sobre os Lugares e Protagonistas do Estudo}

A pesquisa teve como cenário os serviços de saúde da atençáo básica, situados numa capital do Nordeste 
Brasileiro, mais especificamente, Unidades Básicas [UBS] e Unidades Básicas de Saúde [UBSF] vinculadas à Estratégia de Saúde da Família, bem como os grupos nos quais eram realizadas as atividades de Práticas Integrativas e Complementares. Para tanto, foram protagonistas deste estudo, trabalhadores e trabalhadoras que atuavam diretamente nos grupos de PIC's, nos serviços de saúde da atenção básica.

\section{Procedimentos para o Trabalho de Campo, Estratégias de Produção de Dados e Análise}

O trabalho de campo foi delineado a partir de 05 (cinco) etapas: (a) visita à Secretaria Municipal de Saúde [SMS]; (b) mapeamento dos equipamentos de saúde e de profissionais da atençáo básica que desenvolviam atividades em PIC's Grupais; (c) identificação e caracterização das PIC’s Grupais; (d) realização de entrevistas e rodas de conversa; (e) observaçáo-participante nos grupos de PIC's.

Em virtude da diversidade de trabalhos em grupo realizados nos serviços de saúde, selecionamos práticas que atendessem basicamente a dois critérios, previamente estabelecidos: primeiro, práticas grupais que estivessem em sintonia com as concepçóes e princípios das PIC's; e o segundo critério, práticas que, ao longo do processo grupal construíssem algum tipo de interação ou conversação entre os participantes, de modo que possibilitassem uma análise de como se dava, por exemplo, a construção das demandas, relações de poder e participação, valorização das potencialidades e saberes, nível de problematização das experiências, protagonismo do grupo, autogestão, dentre outros. Desse modo, para as duas últimas estratégias de produção de dados deste estudo, entrevistas e rodas de conversa, selecionamos 08 (oito) práticas grupais que se encaixavam nos critérios mencionados anteriormente. Deste elenco, foi possível a observação-participante em 05 (cinco) grupos, com os quais realizamos 06 (seis) entrevistas e 02 (duas) rodas de conversa, com a participação total de 57 (cinquenta e sete) profissionais na pesquisa.

Após a produção e reescritura dos dados relacionados às entrevistas, rodas de conversa e observaçóesparticipantes, delimitamos alguns núcleos temáticos, os quais foram articulados e confrontados com o referencial teórico produzido durante todo o processo da pesquisa.

Em observância à resolução 466/12, do Conselho Nacional de Saúde, que diz respeito à participação de seres humanos em pesquisas, este trabalho foi submetido ao Comitê de Ética de uma Universidade Pública e aprovado em primeira instância, com parecer de número 1.476 .845 .

\section{RESULTADOS E DISCUSSÃO}

\section{Mapeamento dos Profissionais que Realizam PIC's Grupais nos Serviços de Saúde da Atenção Básica}

Observamos que é cada vez mais ampla a inserção das diversas especialidades e domínios de conhecimentos nas PIC's Grupais, o que demonstra a natureza multi e interdisciplinar destas práticas, ainda que algumas profissóes apareçam de modo tímido.

Convém destacar a participação expressiva de Agentes Comunitários de Saúde [ACS's] nas PIC's Grupais. Ao assumirem uma função estratégica na ESF, com o papel de acolher e encaminhar as demandas individuais e coletivas da comunidade, revelam-se verdadeiras potências terapêuticas nos territórios das práticas. Dessa forma, é possível que a significativa inserção dos ACS's nas PIC's Grupais esteja relacionada a, pelo Tabela 1

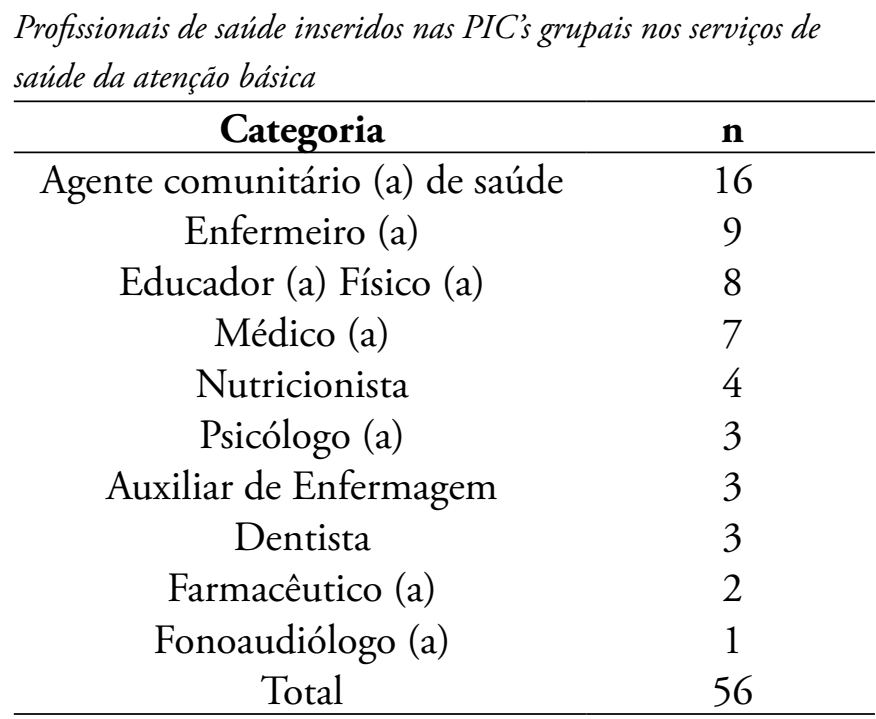

menos, três aspectos: primeiro em razão destes trabalhadores viverem na mesma comunidade na qual está localizada a UBS de sua vinculação profissional. De acordo com Lancetti (2009), os ACS's, quando articulados com outros parceiros da organização sanitária, são fundamentais para fazer funcionar os equipamentos e práticas de saúde.

O segundo aspecto refere-se à facilidade deste profissional em suas práticas educativas transitar por distintos saberes, o popular e o científico, pois, ao mesmo tempo que é portador de um saber técnico possui um 
saber popular inerente à sua classe (Bornstein, Morel, Pereira e Lopes, 2014).

O terceiro aspecto está relacionado ao fato dos ACS's serem vinculados às ações de promoção e prevenção das doenças e agravos e de vigilância à saúde na ESF, contexto em que as açôes integrativas estão incluídas na atenção básica.

\section{Serviços de saúde da Atenção Básica que Realizam PIC's Grupais}

$\mathrm{Na}$ ocasião do mapeamento dos serviços, contactamos 66 (sessenta e seis) equipamentos de saúde da atenção básica, dentre os quais 11 (onze) desenvolviam 22 (vinte e duas) atividades grupais compatíveis com os princípios das PIC's. Das 22 (vinte e duas) PIC's Grupais identificadas, 18 (dezoito) estavam localizadas na ESF e 04 (quatro) em 01 (uma) Unidade Básica de Saúde, esta última ainda não vinculada à Estratégia de Saúde da Família, haja vista que, à época do trabalho de campo, o município realizava a transição para transformar todas as Unidades Básicas em Unidades de Saúde da Família.

\section{Caracterização das PIC’s Grupais}

Nesses contextos, nos deparamos com uma diversidade significativa de configuraçóes de PIC’s Grupais, distintas em termos de categorias, objetivos, demandas e procedimentos metodológicos. Das práticas identificadas, elencamos algumas categorias que traduzem as principais características das estratégias grupais, como: práticas corporais de tradição oriental, práticas corporais gerais, dança, contação de história, grupos de arte e cultura, grupos de caráter sociopolítico e grupos terapêuticos.

As PIC's Grupais relacionadas ao grupo de práticas corporais com tradição oriental, como a meditação, yoga e tai chi chuan, encontram-se açóes que são sustentadas pela filosofia oriental e partem de uma compreensão holística do ser humano, pois considera o corpo como resultado da integraçáo entre os aspectos físicos, emocional, mental e espiritual.

Num segundo grupo de PIC's Grupais identificadas nesta pesquisa, estão localizadas as práticas corporais gerais, como as danças de saláo e zumba, que

\section{Tabela 2}

Caracterização das PIC's grupais realizadas nos serviços de saúde da atenção básica

\section{Categoria}

Intervenção mente-corpo

$$
\text { Dança }
$$

Contação de história

Arte e cultura

Sócio-políticos

Grupos terapêuticos e de ajuda mútua

\section{PIC's grupais}

Meditação, yoga e tai chi chuan e caminhada

Danças circulares, biodança, dança de saláo e zumba

Tenda do conto, tapera da falação, caixa sentimental

Grupos de produçáo de arte, teatro popular em saúde

Teatro do oprimido

Terapia comunitária, grupos operativos apresentam, como ponto de partida um caráter fisicalista, embora possam trazer como consequência a integração corpo-mente.

$\mathrm{Na}$ categoria de PIC's Grupais que tomam a dança como referência estão as danças circulares e a biodança. Como uma PIC grupal inserida no contexto da saúde, ao dançarem em roda, as pessoas colocamse em contato com o seu próprio corpo em movimento, com o seu ser em expressão e com o grupo, ao mesmo tempo que estabelecem e transformam suas relaçóes sociais e aliviam alguns sofrimentos em saúde que, muitas vezes, dispensam as intervençóes a partir da medicalização.

A contação de histórias é uma característica bastante marcante das PIC's Grupais nos serviços, através da realizaçáo de atividades como a tenda do conto ${ }^{3}$, tapera da falação e a caixa sentimental, ferramentas utilizadas nos serviços de saúde nas quais as pessoas são convidadas a identificar em seu cotidiano alguns objetos impregnados de memórias afetivas para, a partir destes, construírem as suas narrativas.

A utilização da arte nos grupos de PIC's pode ser visualizada a partir de experiências que trabalham com artesanatos ou outras produçóes artísticas como um pretexto para a construção de narrativas. Em geral, são grupos compostos por mulheres que, em rodas de conversa, abordam temas e inquietaçóes femininas como forma de promoção de saúde e vida.

3 Ferramenta sistematizada pela enfermeira Jaqueline Abrantes em Unidades Básicas de Saúde, com o propósito estimular os participantes a produzirem narrativas sobre processos de saúde, a partir de objetos biográficos. 
O teatro do oprimido aparece como a estratégia de PIC’s Grupal com caráter sócio-político, por meio do qual são facilitadas algumas atividades teatrais com a concepção que todos os seres humanos são atores, porque agem, e espectadores, porque observam. Todos são, portanto, espect-atores: atuam, agem e interpretam. Nesse sentido, as PIC's Grupais assumem a produção de cuidado em saúde como um ato político, transformador e uma possibilidade de resistência.

Por fim, a última concepção metodológica que embasa o trabalho das PIC's Grupais nos serviços de saúde são as ferramentas de ajuda mútua, como a terapia comunitária, que consistem na troca e intercâmbio de experiências entre os participantes.

\section{Demandas das PIC's Grupais nos Serviços de Saúde}

Dentre as principais demandas que apontaram para a necessidade de implantaçáo das PIC's Grupais nos serviços, destacam-se: a necessidade de reorientação das açôes de educação em saúde voltadas para o tabagismo, gestantes, diabetes e hipertensão e os transtornos mentais graves e leves e o sofrimento difuso.

A primeira demanda, que tem relação com as ações de educação em saúde com os grupos de usuários com enfermidades crônicas, como diabetes e hipertensão, explica-se pela necessidade de reorientação dos processos de trabalho destas práticas, em geral, focados no desenvolvimento de açóes educativas de aprendizado, de diversas formas de viver e lidar com a doença, de esclarecimento e de mudança de hábitos que poderiam influenciar no processo saúde-doença e nas questóes de saúde mais recorrentes em cada território.

A segunda demanda das PIC's Grupais são os transtornos graves e leves, com o intuito de contemplar, no próprio território, tanto as pessoas em acompanhamento, por meio de outros dispositivos, como os Centros de Apoio Psicossocial [CAPS], quanto àquelas que vivem alguma situação de sofrimento, tristeza, desânimo, perda do prazer de viver, irritabilidade, ansiedade e medo, entre outras. Nesse sentido, a Estratégia de Saúde da Família tem contribuído para a desinstitucionalização dos cuidados das pessoas com transtornos mentais na direção de um cuidado em saúde mental territorializado. De acordo com Nunes, Jucá e Valentim (2007), essa proposta favorece a atenção à saúde em equipe multiprofissional, a integralidade (das profissóes, das disciplinaridades e do cuidado), responsabilidade da equipe vinculada a um território de base comunitária, intersetorialidade e interinstitucionalidade.

A terceira e mais expressiva demanda que indicou a necessidade de implantação das PIC's Grupais na atenção básica, denominamos de sofrimento difuso, tendo sido apontada pelos profissionais como um dos problemas mais recorrentes nos serviços de saúde em que a medicalização era a única alternativa.

\section{Relaçôes, Saberes e Fazeres Produzidos no Cotidiano das PIC's Grupais: Diálogos com a Educação Popular}

\section{(a) Valorização dos Saberes e Potencialidades dos Grupos}

As PIC's Grupais identificadas no campo tem suas raízes em matrizes culturais muito próximas de nossa realidade e tomam como ponto de partida, principalmente, a cultura nordestina como referência para a construção das práticas no cotidiano. Nos encontros de PIC's Grupais, todo o ambiente é organizado de modo que as pessoas se sintam como se estivessem em sua casa, entre a cozinha e a sala de estar. Com esta configuraçáo que lembra o ambiente de casa e longe da frieza dos espaços destinados às consultas individualizadas nas quais se enxerga apenas a pessoa doente, as conversas informais e o compartilhamento de experiências que precedem os encontros das PIC's Grupais são importantes para estreitar os laços afetivos e de confiança e proporcionar a ampliação das redes sociais e comunitárias. Para Valla (2001), esses momentos são fundamentalmente produtores de sociabilidade e vida que contribuem para evitar o isolamento das pessoas diante das situações de adoecimento. Assim, o envolvimento comunitário é um fator psicossocial que pode contribuir para o aumento da autonomia e confiança pessoal, do autocuidado, autoestima e vontade de viver para enfrentar melhor os problemas de saúde.

Se os espaços nos quais acontecem os encontros das PIC's nos fazem lembrar que estamos em casa, lugar em que nos sentimos acolhidos, identificados e numa relação solidária e de proximidade com a família e os vizinhos, a decoraçáo é repleta de objetos impregnados de memória e afeto. Entre velas, lampióes, fuxicos, bonecas de pano, lamparina, cartas, fotos e outras tantas lembranças, os participantes das PIC's Grupais são recebidos. Assim, notamos que a utilização de elementos da arte e da cultura popular é um recurso bastante presente nestes espaços como forma de promover o fortalecimento da identidade cultural das pessoas.

A preocupação dos profissionais de saúde em compor os espaços nos quais encontros das PIC's acontecem com os elementos pertencentes à cultura e próximos vida das pessoas, lembra a experiência dos 
círculos de cultura realizados por Paulo Freire, nos quais o educador realizava como primeira etapa do trabalho um levantamento do universo vocabular dos educandos para, em seguida, extrair os temas geradores das reuniôes. As palavras e temas identificados codificavam o modo de vida e as experiências das pessoas a partir de seus referenciais culturais e de mundo.

Como nos círculos de cultura, cada objeto que compóe a paisagem dos espaços das PIC's Grupais remete à possibilidade de construção de um tema que tem a ver com o universo dos participantes e é articulado, também, com as vivências culturais dos profissionais. Por analogia, lançamos mão da ideia de Padilha (2012), no contexto educacional, para aplicá-la aos cenários das práticas, lugar em que os autores e atores se organizam, se relacionam, se contextualizam, trocam experiências, aprendem e ensinam culturas diferentes, reaprendem as suas próprias culturas, aprendem e reconstroem conhecimentos, inclusive os conhecimentos científicos, e levam em consideração todos os repertórios presentes nos grupos. Nessa perspectiva, as PIC's Grupais traduzem uma forma de fazer cultura em que os usuários se sentem sujeitos da história, capazes de produzir modos próprios, solidários e coletivos de viver a saúde porque preserva o diálogo, a participação e a valorização dos seus saberes.

\section{(b) Cultura Oral, Memória e as Narrativas de Ajuda Mútua nas PIC's Grupais}

Ainda que os grupos observados imprimam dinâmicas distintas e próprias de cada lugar, um aspecto comum à condução das PIC's é a contação de histórias, presentes e passadas, como um recurso para a construção das narrativas dos participantes. A ativação das memórias e afetos começa entre a busca e o encontro dos objetos que serão levados para o encontro de pessoas anônimas, desvalorizadas pelos saberes científicos dos profissionais de saúde no cotidiano dos serviços e que narram, nos grupos de PIC's, histórias de dores, alegrias, perdas, reencontros, saudades, recitam poesias, cantam a vida. Então, os objetos são marcados pela identidade de cada um, portanto, biográficos. Para Bosi (2013), os objetos biográficos são aqueles que envelhecem e se incorporam às vidas de seus possuidores, como os relógios da família e os álbuns de fotografias. Cada um representa uma experiência vivida, uma aventura afetiva que vai além da sensação estética ou de utilidade. Mais que isso, remete-nos à nossa identidade e posição no mundo. Nas experiências de contar histórias, semelhantes as que sáo relatadas nos encontros das PIC's, conforme a autora, são episódios que não significam, simplesmente, o ato de reviver, "mas refazer, reconstruir, repensar, com imagens e ideias de hoje, as experiências do passado (...) A lembrança é uma imagem construída pelos materiais que estão, agora, à nossa disposição, no conjunto de representaçóes que povoam nossa consciência atual" (p. 55). Assim, por mais que tenhamos a mesma lembrança ou imagem de um fato, ela ganha outros contornos porque nós não somos os mesmos de outrora, tão pouco nossas ideias e percepçóes da realidade são as mesmas.

Um aspecto relevante das PIC's que tomam a estratégia das narrativas e memórias orais na realização das atividades grupais, além de ser uma forma de valorizar os contadores de causos e histórias, é uma forma de resistência à supremacia da cultura letrada e erudita em detrimento da cultura popular, de base oral. Precisamos entender que nossa tradição na cultura popular é de tradição oral e que as pessoas assumem objetos, situaçôes e acontecimentos como narrativas. Apesar disso, nós, profissionais de saúde, formamo-nos numa perspectiva de ruptura com essa tradição, com uma sobreposição do conhecimento científico e escrito sobre a oralidade dos grupos populares. O discurso acadêmico dos profissionais soa alto e dominante sobre a fala popular (Freire \& Nogueira, 2011).

Ao valorizar, articular e confrontar os diferentes saberes presentes nas histórias dos participantes, as PIC’s Grupais não só assumem a complementaridade como um critério para garantir os diversos modos de cada um dizer a sua palavra, como também estimula a ajuda mútua entre seus participantes, no sentido de identificar outras formas de perceber e reagir às situaçóes de adoecimento e sofrimento. Para Vasconcelos (2013), estes grupos contribuem para o fortalecimento dos vínculos sociais e afetivos, tornam as pessoas iguais pelo compartilhamento de papeis sociais comuns e possibilitam a produção de laços de identificaçáo promotores de maior força emocional e consequente melhoria nas condiçóes de saúde.

\section{(c) Relaçôes de Poder, Participação e Autogestão nas PIC's Grupais}

Sem dúvida, a dimensão da participação está contemplada nas realizaçóes das atividades das PIC's Grupais, especialmente pela incorporação das metodologias participativas como principal fundamento para realização das atividades. Isto é perfeitamente visível, a começar pela própria forma de organização dos ambientes, com pessoas dispostas em círculo, rotineiramente 
discutindo e problematizando algum tema gerador, num clima de leitura coletiva das realidades vividas pelos usuários e na qual o diálogo se impóe como ingrediente importante no protagonismo das pessoas.

Desse modo, as estratégias de condução dos grupos no cotidiano são pensadas de modo a descentralizar o poder e o saber dos profissionais pela adoção de técnicas que promovem relaçôes, de fato, horizontalizadas e que valorizam os saberes e a própria competência grupal. Certamente, os profissionais não pretendem submeter os participantes à condição de meros ouvintes, mas é preciso possibilitar o exercício da vivência da palavra e do corpo, pois partem de uma concepção de cuidado na qual os sujeitos das açóes educativas são os usuários. É uma forma de ampliar as potencialidades de atuaçáo das pessoas frente ao processo saúde-doença, bem como para outros níveis da vida social e política (Carrillo, 2013). Para que isso se concretize, os profissionais utilizam metodologias variadas e de caráter colaborativo, como as dinâmicas de grupo, danças, grupos operativos, teatro do oprimido, terapia comunitária, contação de histórias, rodas de conversas, entre outras. Um elemento importante a ser observado nesse contexto é a frequente preocupação, por parte dos profissionais, em tomar a realidade concreta das pessoas como o ponto de partida para a realização das ações.

Se considerarmos algumas perspectivas metodológicas de atuação no campo da saúde, encontraremos práticas vinculadas a uma concepção formal hierárquica-autoritária, que visa a domesticação das pessoas, outras que são populistas, pois se utilizam do discurso da educação popular, mas trazem resquícios do autoritarismo, e aquelas que têm raízes na ação dialética-dialógica-libertadora, cujo princípio orientador é a participação, horizontalidade e colaboração (Pulga, 2014). Nesse sentido, as PIC's Grupais observadas estáo numa transição entre a perspectiva populista e a dialética-dialógica-libertadora, haja vista que há uma manifestação concreta de promoção da participação pelos profissionais, embora nem sempre se efetive plenamente em todas as etapas do trabalho, como os momentos de produção das demandas, planejamento e avaliação, que pouco envolvem os usuários, muitas vezes, com participaçôes figurativas.

Embora reconheçamos o esforço dos profissionais no sentido de suscitar um grau de envolvimento dos usuários nas PIC’s Grupais, essa participação não pode se restringir à expressão dos saberes nos momentos de execução das práticas, como uma espécie de convocação para as pessoas colaborarem num processo anteriormente previsto, cabendo-lhes apenas obedecer a determinados comandos. As ações em saúde não devem prescindir de um conhecimento mais organizado e táo pouco as vozes das pessoas podem ser substituídas pelos pacotes prévios organizados à imagem e semelhança dos profissionais, pois "quem dá a palavra dá o tema, que dá o tema dirige o pensamento, quem dirige o pensamento pode guiar a consciência" (Padilha, 2012, s.p.). Diante disto, é possível que no interior das PIC's Grupais esteja presente uma cultura de dominaçáo reproduzida em açóes planejadas pelos profissionais e que acabam por expropriar o poder comunitário pela sobreposição do saber necessário, o saber tecnocientífico.

Desse modo, os grupos de PIC's devem possibilitar a transição dos grupos que estáo na condiçáo de assujeitados para grupos sujeito nos quais as pessoas participam efetivamente, opinam, constroem e são ouvidas em suas necessidades. Quando as açôes são inventadas pelo povo, em parceria com os profissionais, daí resulta um sentimento de pertencimento e apropriação de projetos coletivos. Sem dúvida, tais práticas buscam proporcionar o fortalecimento do autocuidado, com graus crescentes de autonomia individual e coletiva, bem como estimulam os vínculos sociais e afetivos.

Com relação às atitudes autogestionárias dos grupos, percebemos como um aspecto especialmente pouco estimulado pelas atividades de PIC's. Mesmo as atividades comunitárias que extrapolam os muros dos serviços, como as comemoraçóes, festas populares, passeios, caminhadas, etc., os grupos apresentam uma significativa dependência dos profissionais. Ainda que estas iniciativas valorizem a criação de espaços que propiciam os intercâmbios culturais e o diálogo e expressem uma extensão da comunicaçáo com os serviços, a autogestáo é uma dimensão que necessita ser exercitada nos grupos de PIC's para que as pessoas ampliem a capacidade de construir modos próprios de caminhar na vida e encontrem formas alternativas e autônomas de se organizar coletivamente, independentes dos equipamentos de saúde.

\section{CONSIDERAÇÓES FINAIS}

As PIC's Grupais expressam muitas potencialidades no cotidiano dos serviços, a começar por se configurarem como um espaço de produçáo de formas de vida que emergem como resistência ao poder médico e medicalizante. Os grupos são espaços de cuidado nos quais as pessoas são acolhidas e cuidadas, manifestam suas emoçóes e afetos, sentem-se pertencentes aos coletivos, constroem redes solidárias e são reconhecidas em seus saberes e práticas. 
Nota-se que a implantação das PIC’s Grupais nos serviços tem contribuído para uma significativa desmedicalização da vida e diminuição de algumas demandas nos serviços, especialmente daqueles usuários com características do sofrimento difuso, problema que tem testado os limites da atenção à saúde e para a qual a medicalização tem sido a única alternativa. A ampliação da visão do processo saúde-doença como princípio orientador das açóes em PIC's Grupais coloca a vida dos sujeitos como centro dos processos de trabalho, pois tenta compreender outros saberes que permeiam o adoecimento, concepção que repercute em modos positivos de agir dos profissionais de saúde diretamente conectados com a realidade e as condiçóes de vida dos sujeitos. Assim, é possível inibir o fortalecimento da medicalização nos territórios para problemáticas como o sofrimento difuso e desenvolver estratégias coletivas e autônomas de produção de vida.

Constatamos, também, que as PIC’s Grupais têm proporcionado a transformação das tradicionais relaçóes nos serviços de saúde, especialmente pela mudança de atitude no que se refere à democratização de saberes e poderes nos grupos, caracterizada pela concepçáo participativa de suas açóes. Esse aspecto se materializa no cotidiano dos serviços por meio da constante valorização dos saberes e potencialidades dos grupos e pelo reconhecimento do diálogo e da participação social e popular como pilares essenciais para a reorientação das açóes educativas. No entanto, a concretização da participação no âmbito das PIC's Grupais tem se constituído como um desafio, seja porque os serviços não estão abertos à escuta dos diversos atores, seja porque somos afetados pela inexperiência da democracia, por medo de perder o poder ou porque náo tivemos a oportunidade de participar de espaços de tomada de decisóes de nossa sociedade.

Sem dúvida, as PIC’s Grupais têm um potencial libertário que está presente desde a sua concepção. Para tanto se faz necessário que os princípios do diálogo e da participação sejam aprimorados com vistas à inserção dos protagonistas das açôes em todas as etapas do processo, desde a construção das demandas, planejamentos, monitoramentos e avaliaçóes até a execução das atividades. Assim, para que as PIC's Grupais se organizem mais efetivamente como espaços de participação mediados pelo diálogo e acolham e legitimem as contribuiçôes do saber popular ao lado do saber técnico-científico, a educaçáo popular pode contribuir para a qualificação da participação em suas açôes, e, consequentemente, na reorientação das diversas estratégias dialógicas que ampliam o pensar e o fazer cotidianos das pic's grupais entre os profissionais de saúde e a população.

\section{REFERÊNCIAS}

Barros, N.F. (2014). O histórico das práticas integrativas e complementares. Comunidade de Práticas. Brasília, DF: Ministério da Saúde. Recuperado de https:// www.youtube.com/results?search_query=nelson+ felice+de+barros+e+pr\%C3\%A1 ticas+integrativas

Barros, N.F. \& Tesser, C.D. (2008). Medicalização Social e medicina alternativa e complementar: pluralização terapêutica do Sistema Único de Saúde. Rev Saúde Pública, 42(5), 914-920.

Bornstein, V. J., Morel, C. M., Pereira, I. D. F. \& Lopes, M. R. (2014). Desafios e perspectivas da educação popular em saúde na constituição da práxis do agente comunitário de saúde. Interface Comunicação Saúde e Educação, 18(2), 1327-1340. DOI: $10.1590 / 1807-57622013.0437$

Bosi, E. (2013). O tempo vivo da memória: ensaios de Psicologia Social. São Paulo: Ateliê Editorial.

Brandão, C. R. (2012). O que é educação popular. São Paulo: Brasiliense.

Brasil. Ministério da Saúde. (2006). Política Nacional de Práticas Integrativas e Complementares no SUS - PNPIC-SUS. Secretaria de Atenção à Saúde. Departamento de Atenção Básica. Série B. Textos Básicos de Saúde. Brasília: Ministério da Saúde. Recuperado de http: // www.saude.gov.br

Carrillo, A. T. (2013). A educação popular como prática política e pedagógica emancipadora. In D. R. Streck \& M. T. Esteban (Orgs.), Educação popular: lugar de construção social coletiva. (16-32). Rio de Janeiro, Petrópolis: Vozes.

Fonseca, M.L.G, Guimarães, M.B.L \& Vasconcelos. E.M. (2008). Sofrimento difuso e transtornos mentais comuns: uma revisão bibliográfica. Rev APS, 3(11), 285-94. Recuperado de http:// www.scielo.br/ scielo.php?pid=S0102-311X2012000100010

Foucault, M. (2002). Os anormais: Curso no Collège de France (1974-1975). São Paulo: Martins Fontes.

Freire, P. \& Nogueira, A. (2011). Que fazer: teoria e prática em educação popular. Petrópolis: Vozes.

Freire, P. (2005). Pedagogia do oprimido. Rio de Janeiro: Paz e Terra.

Freire, P. (1967). Educação como prática da liberdade. Rio de Janeiro: Paz e Terra.

Nunes, M.; Jucá, V. J.; Valentim, C. P. B. (2007). Açóes de saúde mental no programa Saúde da Família: confluências e dissonâncias das práticas com os princípios das reformas psiquiátrica e sanitária. Cadernos de Saúde Publica, 23(10), 2375-2384. Junior, C. R. B. (2013). Análise Institucional e 
Práticas Integrativas e Complementares em Saúde. O caso do Lian Gong. In S. La A Abbate, L. C. Mourão, \& L. M. Pezzato, (Orgs), Análise Institucional \& Saúde Coletiva (pp. 239-261). São Paulo: Hucitec. Lacerda, A; Valla, V.V. (2005) Homeopatia e apoio social: repensando as práticas de integralidade na atenção e no cuidado à saúde. In R. Pinheiro \& R. A. Mattos (orgs.), Construçâo da integralidade: cotidiano, saberes e práticas em saúde (PP. 169-196). Rio de Janeiro: CEPESC/UERJ, IMS: Abrasco.

Lancetti, A. (2009). Clínica peripatética. São Paulo: Hucitec.

Luz, M. T. (2009). Complexidade do Campo da Saúde Coletiva: multidisciplinaridade, interdisciplinaridade, e transdisciplinaridade de saberes e práticas - análise sócio-histórica de uma trajetória paradigmática. Saúde Soc, 18(2), 304-311.

Luz, M. T. (2012). Contribuição do conceito de racionalidade médica para o campo da saúde: estudos comparativos de sistemas médicos e práticas terapêuticas. In M. T. Luz \& N. F. de Barros (Orgs.), Racionalidades médicas e práticas integrativas em saúde: estudos teóricos e empiricos. (15-21). Rio de Janeiro: CEPESC-IMS-UERJ-ABRASCO.

Padilha, P.R. (2012) O círculo de cultura na perspectiva da intertransculturalidade. Recuperado de https://gepffaccat.files.wordpress.com/2012/10/ o-cc3adrculo-de-cultura-na-persepectivaintertransculturalidade-paulo-roberto-padilha.pdf

Pessoa, J. de M. (2013). Festa popular e educação popular: lugares em movimento. In D. R. Streck \& M. T. Esteban (Orgs.), Educação popular: lugar de construção social coletiva. (203-213). Petrópolis: Vozes.
Pinheiro, R. \& Mattos, R.A. de (2004). Cuidado: as fronteiras da integralidade. Rio de Janeiro: Hucitec/ Abrasco.

Pulga, V. L. (2014). A educação popular em saúde como referencial para as nossas práticas em saúde. In $I I$ Caderno de Educação Popular em Saúde. (pp. 123146). Brasília: Ministério da Saúde, Secretaria de Gestão Estratégia e Participativa.

Tesser, C. D. (2010). Medicalizaçâo Social e atenção à saúde no SUS. São Paulo: HUCITEC.

Vasconcelos, E. M. (2008). Abordagens psicossociais: reforma psiquiátrica e saúde mental na ótica da cultura e das lutas populares. São Paulo: Hucitec.

Valla, V.V. (2001). Globalização e saúde no Brasil: a busca da sobrevivência pelas classes populares via questão religiosa. In E. M. Vasconcelos (Org.). A saúde nas palavras e nos gestos (pp. 39-62) São Paulo: Hucitec.

Vasconcelos, E. (2013) Manual de ajuda e suporte mútuos em saúde mental: para facilitadores, trabalhadores $e$ profissionais de saúde e saúde mental Rio de Janeiro: Escola do Serviço Social da UFRJ; Brasília: Ministério da Saúde, Fundo Nacional de Saúde.

Vasconcelos, E. M. (2010). Educação popular e atenção á saúde da família. São Paulo: Hucitec.

\section{Endereço para correspondência:}

Isabel Fernandes de Oliveira

Campus Universitário UFRN, Lagoa Nova

CEP: 59078-970 - Natal/RN

E-mail: fernandes.isa@uol.com.br

Recebido em 15/06/2017

Aceito em 14/08/2017 